\title{
STANDARDS FOR THE MANAGEMENT OF SWABS, NEEDLES AND INSTRUMENTS IN THE OPERATING THEATRE
}

\author{
A Astrop, $\mathrm{T}$ van der Merwe and $M$ Muller
}

\begin{abstract}
The management of swabs, needles and instruments in the operating theatre is a high-risk and problem-prone area for the operating theatre nurse. The purpose of this research is to formulate specific standards on the management of swabs, needles and instruments in the operating theatre to ensure the safety of the patient. An exploratory and descriptive research design was used and executed in 3 hospitals of a private hospital group in Gauteng. A structured two phase process was followed, ie the development phase and the validation phase. This last phase was done by means of deliberate debate. It is recommended that these standards be implemented, tested and validated on a national basis and a monitoring and evaluation system should be developed to ensure nursing compliance with these standards.
\end{abstract}

\section{UITTREKSEL}

Die hantering van deppers, naalde en instrumente in die operasiesaal is 'n hoë risiko, probleemgerigte en hoë frekwensie interaksie vir die operasiesaalverpleegkundige. Die doel met hierdie navorsing was om spesifieke standaarde vir die hantering van deppers, naalde en instrumente in die operasiesaal te formuleer ten einde die veiligheid van die pasiënt te verseker. 'n Verkennende and beskrywende standaardformuleringsontwerp is gebruik en binne die konteks van 'n privaathospitaalgroep (drie hospitale) in Gauteng uitgevoer. 'n Gestruktureerde twee-fase proses is uitgevoer, naamlik die ontwikkelings- en valideringsfases. Die laaste fase is deur middel van doelgerigte debatvoering uitgevoer. Dit word aanbeveel dat hierdie standaarde geimplementeer en uitgetoets word en op 'n nasionale basis gevalideer word. Verder word aanbeveel dat ' $n$ monitering-en evalueringstelsel ontwikkel word om te bepaal in hoe ' $n$ mate die verpleegkundiges aan hierdie standaarde voldoen.

\section{INTRODUCTION}

The operating theatre nurse is professionally-ethically responsible for establishing and maintaining a safe and therapeutic environment during surgical interventions in the operating theatre. Certain policies and procedures should be in place to guide peri-operative nursing care. This article focuses on the management of swabs. instruments and needles during surgical interventions in the operating theatre. The nurse and surgeon have a shared responsibility regarding the control of these swabs, instruments and needles. Such control in the operating theatre is a high risk, problem-prone and high volume charge and control has to be done in terms of strict regulations in this regard (Atkinson, 1992: 219; Makheta, and Smith 1986).
An operating theatre nurse manager attended World Congresses for Operating Theatre Nurses in 1991, 1993 and 1995. In 1991 the new method of swab control was first discussed and in 1993 was proposed for implementation in the South African hospital group in which this research is conducted. A theatre forum was established within the group made up of nursing service managers and operating theatre unit managers and through the endeavour of this dynamic group it was decided to implement this new method of swab control

It soon became clear that standards on the management of swabs, instruments and needles for the operating theatre had to be compiled to ensure quality nursing care in this regard. The aim of this research is to formulate standards for the management of swabs, instruments and needles in the operating theatre within a specific private hospital group in Gauteng.

\section{TERMINOLOGY}

Standard

A standard is a written description of the expected or desired level of performance by the operating theatre nurse in the management of swabs, needles and instruments during a surgical intervention.

Swabs

Swabs are resources used for absorbing blood and fluids, protecting tissues, applying pressure or traction and dissecting tissue during a surgical intervention. A radio-opaque thread or marker is incorporated into commercially manufactured swabs

There are different types of swabs: gauze swabs 3" $\times 3$ 3" $(7.6 \times 7.6) \mathrm{cm}$ which are used for small incisions; 4 " $\times 4$ " $(10 \times 10) \mathrm{cm}$; raytec swabs or dissecting swabs and other swabs such as:-

- large abdominal swabs; with attached tapes

- small abdominal swabs; usually used in the bladder

- peanut swabs or lahey swabs; small round gauze sponges used for blunt dissection or to absorb fluid in delicate procedures

- large and small tonsil swabs which are cotton filled gauze with a cotton thread attached

- neuro-patties made of compressed rayon or cotton, used moist on delicate structures such as the brain or spinal cord.

Needles and instruments

Needles and instruments are surgical aids used during a surgical intervention that can cause injury/complications if left in the patient after completion of the operation.

\section{Nurse}

A nurse in this context is a registered nurse with or without the qualification in operating 
theatre nursing science, who scrubs for surgical procedures in theatre.

\section{New method}

New method implies the counting of swabs in fives and doing away with swab racks in the operating theatre.

\section{Old method}

Old method refers to displaying swabs on a swab rack in the operating theatre.

\section{LITERATURE REVIEW: QUALITY OPERATING THEATRE NURSING CARE IN THE MANAGEMENT OF SWABS, NEEDLES AND INSTRUMENTS}

Quality operating theatre nursing care refers to the substantial compliance with standards. The focus in this study is on the standards for swabs, needle and instrument control in the operating theatre. The process of quality improvement involves the formulation of standards, monitoring and evaluation of the real performance against these standards and responding by correcting the nursing interactions which do not comply (Muller, 1996: 228). Quality nursing necessitates the implementation of a specific quality improvement programme to meet the needs of the nursing service. The formulation of specific standards is one of the first steps in the formal process of quality improvement and reflects the view of the nursing service on quality as well as accepted criteria for excellence (Muller, 1996: 228)

Standards are classified according to structure, process and outcome. Structure includes all structured elements needed to implement a standard safely. Process reflects the scientific manner in which the nurse performs the action, whilst outcome reflects the intention in both the structure and process standards (Affara \& Styles, 1991; Muller, 1996: 228-232).

The operating theatre nurse has got certain professional responsibilities regarding the management of $s w a b s$, needles and instruments in theatre. These responsibilities are discussed in accordance with the following principles given by Makheta and Smith (1986) and Ackinson (1992).

\section{a) Prior to sterilization}

Use clean, uncontaminated, new swabs. Check all swabs and shake well before folding and packing; no wool, threads or pieces of lint should adhere to the swab. Swabs must be $X$-Ray opaque and abdominal swabs must have $25 \mathrm{~cm}$ tapes. The first and second checker must do a simultaneous check. Each bundle must contain five swabs, abdominal, raytec and tonsil swabs are kept together with tape or a rubber band. Point balls are sewn together and each bundle must contain a signed document. b) The swab control document

The swab control document must have a date, the types of swabs, the number of bundles and two signatures with designations.

\section{c) Pre-pack sterile swabs}

Pre-pack sterile swabs are large abdominal swabs with a paper tag around series, as a control document. The information on the peel-packet serves as a control document for the raytec swabs. Unsoiled leftover swabs must be returned to Central Sterilising Department in a clean container for recycling.

\section{d) Before the operation}

Before the operation swabs may not be checked in the ante-rooms and one of the two people counting must be a registered nurse. The floor nurse, using an aseptic technique, opens the pack and gives the scrub nurse the swabs who then will remove the rubber band or paper tag, document, check and hand this to the check nurse. The scrub nurse holds the bundle up and checks that each swab has a secured tape and an opaque indicator. He/she checks each swab separately into a bowl while counting audibly and must not count one bundle on top of another. The floor nurse must count audibly with the scrub nurse. If extra swabs are required during the operation, the same procedure is to be followed with number added on, e.g. $5+5+5$

Small dissecting swabs (laheys) are counted by holding one secure between fingers, counting that one and then pointing with the finger to the remaining four which are then placed in a gallipot. Ensure that each has an $\mathrm{X}$-Ray opaque indicator. If any bundle of swabs opened is found to be incorrect, the swabs and document must be removed from the theatre to prevent later confusion. The incorrect swabs must be given to the unit manager who must follow up this occurrence. No opened swabs are to be allowed in theatre if they are not counted. Swabs may not be used for cleaning theatres.

\section{e) Use of the white board in theatre}

The white board in theatre must reflect at least the following information:- the patient's name, identification number, name of the doctor, procedure to be done, large abdominal swabs $5+5$, raytec swabs $5+5$ and lahey swabs $5+$ 5 .

\section{f) Countdown during operation}

The countdown during a surgical intervention must be carried out by the original two counters. Soiled swabs are discarded from the operative field into an open basin on top of the kick-about (roundabout). The scrub nurse must open up a raytec swab before discarding. The floor nurse will wear gloves and use a Rampley sponge holder to touch swabs. When he/she has 5 swabs, the anaesthetist's attention is drawn to assess bloodloss. When the countdown of swabs commences, the check nurse will touch each swab with the swab holder, audibly count with the scrub nurse and place it in a plastic bag, counting once again to five. Dissecting swabs and raytec swabs are put in separate plastic bags which do not leave the theatre. The number five (5) on the board is crossed out -this indicates that this bundle is out of circulation. This procedure is repeated for every five (5) swabs of the same type on the rack. Before closure of the cavity, an audible check is done of the remaining swabs on the rack and those in use on the trolley and operating field. A line is drawn through the remaining fives on the board, for example:

- abdominal swabs $\$+\$+5+5$

- raytec swabs $\$+\$+5$

- lahey swabs \$f+5

\section{g) Rules for counting swabs}

The rules for counting swabs in theatre accord with the scrub nurse's specific preference, complying with at least the following: there should be a minimum of three (3) counts of swabs, although this is not a hard and fast rule. If the scrub nurse is doing a long difficult procedure using many swabs she can do five to six counts. It is up to the individual but the first swab count must be done before the peritoneum is closed, the next count is done before fascia is closed and the last count before the skin is sutured.

\section{h) Lahey swabs}

Lahey swabs are not removed from the trolley, but checked into a gallipot/receiver.

\section{i) Interaction with surgeon}

It is important that the correct swab count is reported to the surgeon who must acknowledge this.

\section{The procedure for a lost swab, instrument or needle}

If the count is incorrect, inform the surgeon and do a recount. The missing item must be looked for in the surgical cavity as well as in the theatre. In the event of the missing article not being found, the scrub nurse must inform the registered nurse in charge. X-Rays, must be taken and if the article is seen, the surgeon must re-open the cavity. If no article shows on $X$-Ray the surgeon records on the patient's file stating the missing article does not show on $X$-Ray. The scrub nurse will endorse the facts about missing items in red on the operative form and in the operation register. The scrub nurse and check nurse must write a statemen and hand it to the nurse in charge. The original statements are photo copied to distribute to the following significant supervisors: Chief Nursing Service Manager, Clinical Manager Theatre Nursing Service Manager, Scrub Nurse and Floor Nurse. 


\section{a) Control of instruments and needles}

All instruments must be counted audibly by the scrub nurse. The floor nurse ticks these off on the operating check list. The major sets are checked first, for example laparotomy set, then extra instruments for example, the gastrectomy extras. Particular care must be taken when counting screws, such as bladder retractors and tips of suction nozzles before the peritoneum is closed. All instruments are counted by the original two checkers, the surgeon is notified and must acknowledge the information. The instrument count is recorded in a similar fashion to the swab count.

\section{Needles}

Needles, such as Mayo's are counted audibly by the scrub nurse and check nurse and the number should be recorded on the board. They are kept in a gallipot on the trolley when not in use. Before the peritoneum is closed, an audible count is done by the original two people and the number on the board crossed through. The foil packets from which the atraumatic sutures are taken, are kept until the end of the case so that the suture packets and needles correiate.

A final needle count is done before the peritoneum is closed and reported to the surgeon who must acknowledge this. It must be recorded on the patient's file that the needle count is correct.

Procedure to be followed when a swab, needle or an instrument is found in a previous operating site

a) A known swab, needle or instrument to be removed

The nursing unit manager of the theatre complex must receive the removed item and place it in appropriate container such as a specimen bag for a swab or instrument and a specimen bottle for a needle. The patient's particulars must be reflected on the attached sticker. Swab, instrument and needle counts and completions of records are to be carried out as previously outlined. A statement must be written by the scrub nurse and floor nurse which are handed to the nurse manager.

\section{b) Removal of foreign body}

If a foreign body tums out to be a swab, needle or instrument left behind during a previous operation, the item is identified and the guidelines for the previous procedure are followed.

Procedure to be followed when the scrub nurse and floor nurse are relieved during a procedure in which instruments, swabs and needles are counted

In exceptional circumstances where a case is expected to overlap nurses' shifts, the scrub nurse and check nurse may be relieved. The original scrub nurse and check nurse must complete a full count of all the instruments and swabs and record the information. The relieving scrub and check nurses must do a full count of instruments and swabs while the original scrub nurse and floor nurse are in attendance. Once the relieving team is satisfied that all instruments and swabs are accounted for, the original team may leave and complete relevant documents. At the end of the operation the relieving team will count instruments and swabs as in normal circumstances. The operating form and operation register must reflect full particulars and signatures of both the original and relieving team.

\section{RESEARCH DESIGN AND METHOD}

An exploratory, descriptive design was followed, using a structured standard formulation method consisting of the development and validation phases. During the development phase a literature study was performed to serve as the theoretical basis for the standards. Semi-structured purposeful debates were held to clarify certain issues pertaining to staff and whether the new method of swab, needle and instrument management was acceptable to the theatre nurses. The purpose of the debates also was to ensure ownership of the standards and to verify the content validity of the provisionally formulated standards. Because these standards are in use within the context of a specific private hospital group in Gauteng, national validation was not performed.

\section{Sample}

The research was conducted in a private hospital group involving three hospitals in Gauteng. The professional nursing and medical staff formed the target population. The sample for the formulation and validation of the specific standards consisted of two groups. The first group comprised the members of the committee for standard formulation ie the deputy nursing service manager (professional nurse), operating room charge nurse and deputy, infection control nurse, clinical tutor and a practising general surgeon of the three hospitals.

Convenience sampling was used to include the professional scrub nurses on duty between the months of June and July 1995. A total of 52 scrub nurses took part in the debates of whom 33 were in possession of the operating theatre certificate.

\section{Reliability}

Measures implemented to ensure reliability of validation results lay in ensuring that a representative number of participants involved in operating theatre nursing in the three hospitals had equal opportunity to give input to the provisional standards.

\section{Validity}

A literature study on provisional specific standards was carried out to ensure theoretical or content validity of the standards. The standards were validated by the role-players (refer to sampling method) during the validation phase. The completed provisional standards were then presented to the regional Operating Theatre Nurses' Forum for determination of face-validity. The final stage of validation lies in the testing and implementation of the standards before national validation can be done.

\section{Ethical considerations}

Permission was granted by management and heads of departments to undertake this research. Participants individually gave permission to participate in the process of standard formulation as well as the debates.

\section{RESULTS}

The following standards were formulated and validated:

\section{Philosophy}

There is a written philosophy in the operating theatre reflecting at least the following:

1.1 the rights of the patient in terms of a safe environment:

1.2 the role of the nurse in the management and control of swabs, needles and instruments during surgical interventions;

\section{Policies and procedures}

There is a written policy and procedure in the operating theatre on at least the following:

2.1 the management of swabs, needles and instruments during surgical intervention;

2.2 lost swab, instrument or needle procedures.

2.3 safety measures when the scrub nurse is relieved during a procedure;

\section{Equipment and stocks}

3.1 Only swabs with an X-Ray opaque line running through them are used.

- large abdominal swabs

- small abdominal swabs

- large dissecting swabs (raytec)

- small dissecting swabs (lahey or peanuts)

- large tonsil swabs

- small tonsil swabs

- vascular swabs (Plugging)

- neuropatties 
3.2 At least the following are available:

- sterile latex gloves

- roundabout or single basin stand

- basin or bucket

- Ramply sponge holder

- white board on wall with white board marker

- control document

- plastic bags in which to place used swabs in

- instruments needed for the specific surgical operation

- suture material containing needles

- protective eye wear (goggles); mask; aprons; sterile gowns.

\section{Packing of swabs}

The nurse or health care worker ensures safe and accurate packing of swabs by the following:

4.1 use clean uncontaminated swabs;

4.2 check all swabs for any loose threads or pieces of lint adhering to swab;

4.3 ensure all swabs are X-Ray opaque;

4.4 check abdominal swabs have a $25 \mathrm{~cm}$ tape and that it is secure;

4.5 count all swabs in bundles of five;

4.6 check that two people do a simultaneous check;

4.7 ensure swab control document contains at least the following:

- date

- type of swab

- number of bundles

- two legible signatures of checkers;

4.8 tape all bundles with tape or rubber band;

4.9 ensure that all swabs leaving the C.S.S.D. comply with the following:

- autoclave tape has changed colour

- packaging is sealed and intact

- date on packaging plus the expiry date is within a six week period;

5. The foor/circulating nurse in theatre ensures safety in the management of swabs, needles and instruments by at least the following:

5.1 check expiry dates of swabs and packaging for sterility;

5.2 use an aseptic technique to open the outer pack of swabs and give to the scrub nurse;

5.3 ensure there are no bundles of open swabs in the theatre

5.4 write on white board the patient's name and number, doctor's name, procedure large abdominal swabs e.g. $5+5+5$, raytec swabs e.g. $5+5$, lakey swabs e.g. $5+5$, needles e.g. $1+1+1$;

5.5 if any swabs are found to be incorrect, give entire bundle with control document to theatre charge nurse, to investigate; assemble all equipment:

- roundabout

- basin

- sponge holder

- plastic bags;

5.6 protective gear: gloves, mask, apron and goggles;

5.7 count swabs audibly with scrub nurse;

5.8 check the instruments with instrument check sheet with scrub nurse prior to procedure;

5.9 write on white board in bundles of five the number of swabs given;

5.10 place swabs in basin once the surgical procedure has commenced:

5.11 count audibly, touching each swab with a spongeholder;

5.12 draw anaesthetist attention to used swabs to evaluate bloodloss:

5.13 count swabs shown into plastic bag when five swabs have been discarded;

5.14 use a separate bag for different types of swabs;

5.15 ensure swabs in bags do not leave theatre till final count is done and operation is over:

6. The scrub nurse ensures safe management of swabs, needles and instruments by complying with at least the following:

6.1 scrub hands / wear sterile latex gloves according to the procedure;
6.2 receive swabs from circulating nurse check inner packaging and expiry date on control document;

6.3 audibly with circulating/floor nurse count swabs into separate basins into bundles of five (never one on top of another);

6.4 keep control document (serves as a check for number of swabs used);

6.5 hold abdominal swabs up and check tags are firmly attached;

6.6 instruct nurse to write swab count on board;

6.7 count instruments audibly with nurse according to check list;

6.8 coun: all screws and bolts or retractors;

6.9 count sutures containing needles with nurse and instruct her to write number on board:

6.10 lahey swabs are counted by holding one and touching after four (lahey swabs do not leave the trolley):

6.11 when discarding raytec swabs, open up the swab;

6.12 when five swabs are discarded count them down onto plastic bag with the floor nurse; all used swabs are displayed in the basin

6.13 ask anaesthetist to observe bloodloss

6.14 instruct nurse to put an oblique line $(\Omega$ through bundle of five checked, re-count into plastic bag putting another line through i.e.

- abdominal swabs $5+5$ with oblique line

- raytec $5+5$ with oblique line

- lahey $5+5$ with oblique line;

6.15 do first count before peritoneum is closed:

6.16 do second count before fascia is closed;

6.17 do third count before skin is sutured;

6.18 count instruments with nurse before peritoneum is closed:

6.19 count suture needles with nurse and compare with suture packets and check off on white board;

6.20 correct counts are reported to surgeon who must acknowledge this audibly;

6.21 document all swabs, sutures used on costing sheet 
7. The procedure for a lost swab, needle or instrument complies with at least the following:

7.1 The scrub nurse will:

- inform surgeon of missing item;

- inform the theatre charge nurse;

- search operation field thoroughly;

- have relevant X-Rays taken of patient according to doctor's prescription;

- if swab, needle or instrument is not found, all particulars of incident are recorded in patient's file and operating room register;

- write a statement in terms of the hospital policy;

7.2 If the swab, needle or instrument is found in a previous operating site the scrub nurse will:

- give the swab/needle/instrument to operating theatre nursing service manager;

- attach patient's particulars on label

- carryout counts of swabs, needles and instruments and complete records as previously outlined;

- write statement as outlined before and give to the appropriate people.

8. Safety is ensured when the scrub nurse and circulating nurse are relieved during a procedure during which instruments are counted.

8.1 The scrub nurse will:

- ask the surgeon if she may be relieved;

- complete a full count of all the instruments, swabs and needles with relieving scrub nurse and circulating nurse;

- leave when relieving team are satisfied that all instruments, needles and swabs are accounted for;
- at end of operation, relieving team will count swabs, needles and instruments as in normal circumstances;

- the patient's file and theatre register must reflect full particulars and signatures of both the relieving and original team.

\section{LIMITATIONS}

Time was too limited to do an in-depth study due as the researcher was a student on the operating theatre nursing science diploma course. Being a student meant the researcher was not in a position of authority to implement change and therefore research was limited to three hospitals within the group. Time also did not allow the researcher to validate the standards in the quantification phase by determination of the statistical content validity of each standard.

\section{RECOMMENDATIONS}

The following recommendations are made:

- The implementation and testing of these standards with flexibility allowed for specific needs of the individual, operation performed and surgeon's preference.

- Formation of a Standard Formulation Committee in every Operating Theatre Service.

- Continuous revision of these standards.

- National validation of the standards.

- The development of a monitoring and evaluation system to evaluate the compliance with these standards, as part of the Operating Theatre quality improvement programme.

\section{CONCLUDING REMARKS}

The formulation of standards is the first step in the quality improvement programme of the operating theatre. It is important to identify those nursing or clinical interactions that may have high risks, such as the management of control of swabs, needles and instruments. The process of quality improvement has to be followed through by means of evaluation to see if nurses are indeed complying with the standards.

\section{Acknowledgements}

This research was done as part of the course for Operating Theatre Nursing Science at the Rand Afrikaans University. Many thanks to all the professionals that participated in the formulation of these standards.

\section{REFERENCES}

Affara, F.A. \& Styles M.M. (1991): Nursing regulation: from principle to power. GENEVA: International Council for Nurses.

Atkinson, L.J. (1992): Berry and Kohn's Operating Room Technique. USA: Mosby.

Kuit, J.E. \& vam der Merwe, T. (1994): Specific Nursing Standards. JOHANNESBURG: University of the Witwatersrand Central Printing Unit.

Le Bron, B. (1995): Notes given as the lecturer at RAU for Operating Nursing Science. JOHANNESBURG: Unpublished.

Makbeta, P.P. \& Smith, E. (1986): Personal notes on the control of swabs, needles and instruments. JOHANNESBURG: Unpublished.

Meeker, M.H. \& Rothrock, J.C. (1992): Alexander's Care of the Patient in Surgery. USA: Mosby

Muller, M.E. (1996): Nursing dynamics. DURBAN: Heinemann.

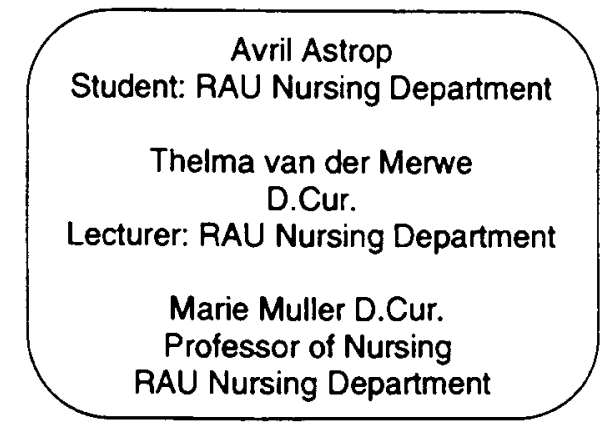

